\title{
The Effect of Fan Blade Radiator Gas Turbin Generator Angle on Auxiliary Cooling Water System Performance
}

\author{
Erryawan Kusuma ${ }^{1}$, Agus Sigit Pramono²
}

\begin{abstract}
Auxiliary Cooling Water System (ACWS) on Gas turbine Blok 1 No 3 Muara Karang has declined its reliability because of 4 fan radiators must be operated due to increasing ambient air temperature and increase inspection interval from 8000 to $32.000 \mathrm{EOH}$ after Upgrade in turbine part. This study aims to optimize Radiator ACWS performance by increasing the cooling fan air mass flow by changing the fan blade angle so it can be operated with 3 fan on and 1 fan standby. This research began with taking data each measurement at $11^{\circ}, 13^{\circ}, 15^{\circ}, 17^{\circ}$, and $19^{\circ}$. Then, it will simulated by software to know the influence of air mass flow addition due to the change of the blade fan angle to the radiator water outlet temperature and to know the input operating parameters when the temperature outlet radiator is $46^{\circ} \mathrm{C}$. The results of this study is validation of experimental and numerical data calculations that have errors below $5 \%$. The maximum angle of fan blade can be set until $19^{\circ}$. At $16.7^{\circ}$ with operation 3 of 4 fan on, radiator temperature output is $46^{\circ}$ and heat disposed is $627.2 \mathrm{~kW}$ where this value is the same value as the current condition.
\end{abstract}

Keywords — Radiator Outlet Temperature , Cooling Fan, Blade Fan Angle Angle

\section{INTRODUCTION}

$\mathrm{O}$ ne of the power plants in Muara Karang is Block 1 consisting of 3 Gas Turbine (GTG1.1, GTG1.2 and GTG1.3) each of which capacity has a $105 \mathrm{MW}$ and 1 Steam Turbine (STG1.0) has 185 MW (Total 500 MW). In order to increase the output, efficiency and availability, Block 1 done upgrade combuster and turbine side on one of units, GTG1.3 on 2016 with the Advanced Gas Path (AGP) [1] and Extendor [2]. One of the results is maintenance interval increased from 8000 operating hours to 32,000 operating hours or 1,200 start. Thus, it will extend the inspection interval 33\%. By increasing inspection interval GTG1.3 as seen in fig 1 , it is necessary to make maintenance changes on the Auxiliary equipment GTG.13 so that during the operation of 32,000 hours it is attempted to have no interference from the auxiliary equipment that make the performance of GTG1.3 down. ACWS is one of auxiliary equipment of gas turbine that serves to cool lubricant oil, Generator, Atomizing air and support turbine where that there is equipment called cooling fan which have maintenance interval of every $8000 \mathrm{EOH}$.

Cooling Fan functioned to suck the air cooler Radiator. Radiator consist of 2 bays, and each bay has 2 suction fans. Totally there are 4 Radiator that are operated (no backup unit fan). The ability of Radiator to discharge the heat is very important as one of the component which is cooled by the ACWS is oil lubricant that has operation limit which if

\footnotetext{
${ }^{1}$ Erryawan Kusuma is with Engineering Power Plant Division, Pembangkitan Jawa Bali Company, East Java, Indonesia. E-mail: erryawan@ptpjb.com.

${ }^{2}$ Agus Sigit Pramono is with Mechanical Engineering, Institut Teknologi Sepuluh Nopember, Surabaya, 60111, Indonesia. E-mail: pramono1065@gmail.com.
}

oil lubricant temperature reach $68^{\circ} \mathrm{C}$ it will turn on the alarm and make a trip if it reaches $73^{\circ} \mathrm{C}$ [3]. As a result of increasing temperature ambient over time, there is also a decline in performance of the ACWS Radiator. By now, if one of the cooling fan is turn off and the air temperature ambient is over $34^{\circ} \mathrm{C}, 3$ fan operated cannot able to protect oil lubricant temperature under temperature alarm limit and gas turbine must be decreased its loading until 15-25 MW so that the oil temperature will not be fixed at $73^{\circ} \mathrm{C}$ Trip temperature. Based on this condition, the research is taken by optimizing the cooling fan performance so that the ACWS Radiator is able to discharge the heat at maximum load and the high air temperature of three cooling fans without any increase in oil lubricant temperature. From previous research [4], by added the fan's angle will increase air mass flow rate until the stall effect started to happen and the motor power is still sufficient. Other studies [5] the influence of angle of attack and hub tip ratio of mass flow rate in axial fan with radial constant speed, using a CFD is obtained by varying the angle of the blade fan $30^{\circ} \mathrm{C}$ to $70^{\circ} \mathrm{C}$ and obtaining maximum yield at $45^{\circ} \mathrm{C}$ to $50^{\circ} \mathrm{C}$ and then starting to decrease with increasing angle of attack.

\section{METHOD}

This study aims to get the effect of a change in the angle of the fan blade every $2^{\circ}$ towards the air suction capacity radiator and got the output water temperature data, as well as radiators heat discharged by a fan three operating in every variation of the angle of the fan blade. Calculation of air suction capacity is obtained from the air speed data enters the radiator by doing experiments on the unit is not operated. To calculate the temperature, the heat discharged is accompanied by a simulation using the Cycle Tempo 5.1 
software [6] with the input data from the operation data when oil temperature condition closest to the alarm temperature $68^{\circ} \mathrm{C}$ and the results of the calculation of the air capacity. ACWS system and operation data could be refers to fig 2a and $2 \mathrm{~b}$, for a detailed picture of the fan, blade angle setting procedure [3], point data retrieval experiment [7] and measurement results are on Figure 3 respectively.

Existing Inspection Cycle

\begin{tabular}{|c|c|c|c|}
\hline \multicolumn{2}{|l|}{ MI } & 8,000 & \\
\hline
\end{tabular}

Inspection Cycle After Upgrade

\begin{tabular}{|c|c|c|c|}
\hline MI + & 32,000 & HGPI & 32,000 \\
\cline { 3 - 4 } & & & \\
\hline
\end{tabular}

Figure 1. GTG Inspection Interval 13 before and after Upgrade.

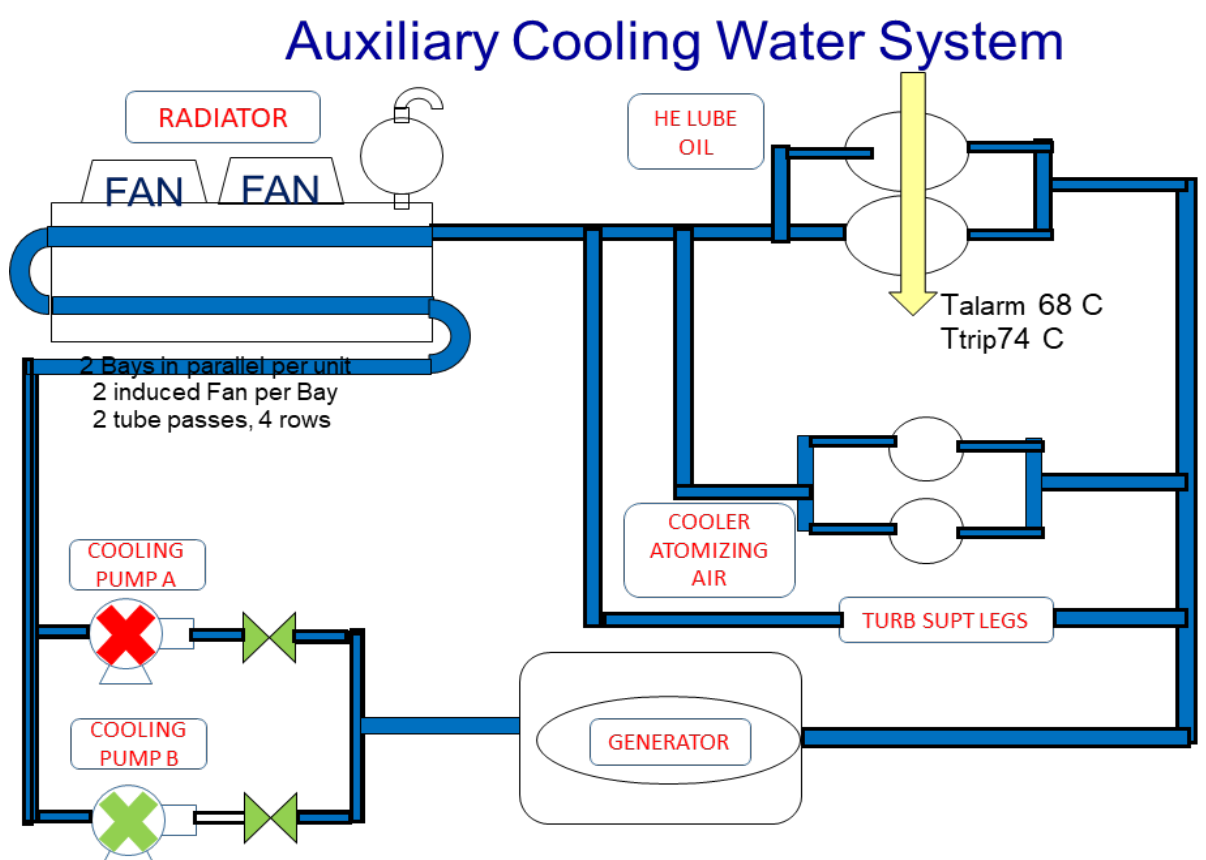

Figure 2. Sceme pipe diagram of ACWS

TABLE 1.

DATA TABLE OPERATIONS OF ACWS

\begin{tabular}{cccccccc}
\hline \hline \multirow{2}{*}{ Date } & \multirow{2}{*}{ Time } & Load & $\mathbf{T}_{\text {ambient }} \mathbf{C}$ & \multicolumn{2}{c}{ Radiator } & $\mathbf{T}_{\text {lube oil header }}$ & $\mathbf{T}_{\text {lube oil tank }}$ \\
\cline { 5 - 8 } & & & & $\mathbf{T}_{\text {in }} \mathbf{C}$ & $\mathbf{T}_{\text {in }} \mathbf{C}$ & $\mathbf{T}_{\text {out lube oil }}$ & $\mathbf{T}_{\text {in lube oil }}$ \\
\cline { 5 - 8 } & & $\mathbf{M W}$ & ${ }^{\circ} \mathbf{C}$ & ${ }^{\circ} \mathbf{C}$ & ${ }^{\circ} \mathbf{C}$ & ${ }^{\circ} \mathbf{C}$ & \\
\hline $13 / 4 / 17$ & 0 & 106.5 & 27 & 47 & 41.5 & 62 & 70 \\
$13 / 4 / 17$ & 2 & 107.7 & 27 & 47 & 41.5 & 62 & 70 \\
$13 / 4 / 17$ & 4 & 107.3 & 27 & 46 & 41 & 61 & 70 \\
$13 / 4 / 17$ & 6 & 107.2 & 27 & 46 & 41 & 61 & 70 \\
$13 / 4 / 17$ & 8 & 104.1 & 30 & 48 & 45 & 63 & 72 \\
$13 / 4 / 17$ & 10 & 102.2 & 32 & 49 & 45 & 64 & 72 \\
$13 / 4 / 17$ & 13 & 101.6 & 34 & 49 & 46 & 65 & 73 \\
$13 / 4 / 17$ & 15 & 102.5 & 34 & 48 & 45 & 64 & 73 \\
$13 / 4 / 17$ & 17 & 102.7 & 33 & 48 & 45 & 64 & 73 \\
$13 / 4 / 17$ & 20 & 107.7 & 32 & 48 & 44.4 & 65 & 74 \\
$13 / 4 / 17$ & 22 & 106.8 & 30 & 48 & 44.5 & 65 & 74 \\
\hline \hline
\end{tabular}




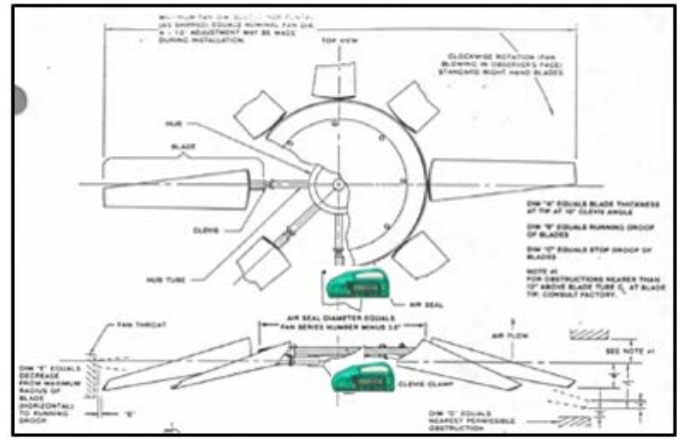

(a)

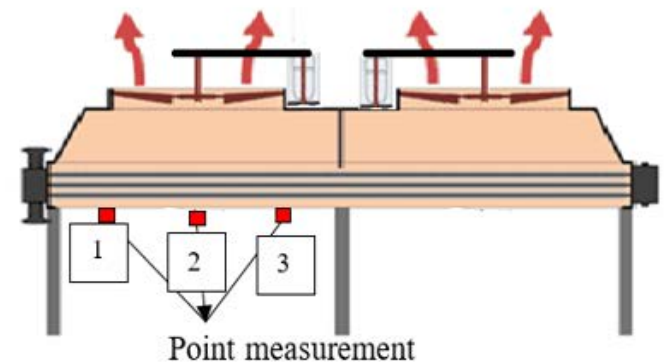

(b)

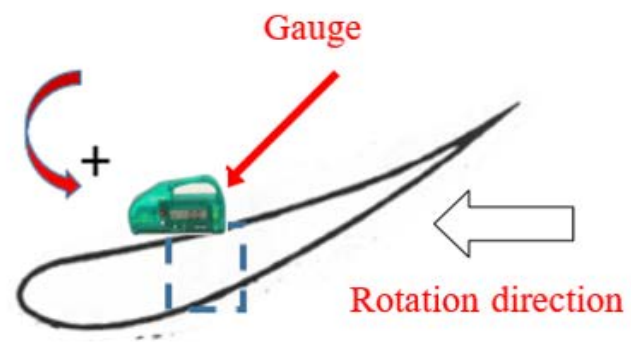

(c)

Figure 3. Fan Radiator (a). The gauge position on the fan;(b) The position of the experimental data retrieval; (c). Setting method the blade fan angle angle.

TABLE 2.

FAN RADIATOR EXPERIMENTAL DATA TABLE

\begin{tabular}{cccccc}
\hline \hline \multirow{2}{*}{ No } & Sudut $\left({ }^{\circ}\right)$ & $\mathbf{v}(\mathbf{m} / \mathbf{s})$ & $\boldsymbol{\rho}(\mathbf{K g} / \mathbf{m} 3)$ & $\mathbf{A ~ ( K g / m 3 )}$ & $\dot{\boldsymbol{m}} \mathbf{K g} / \mathbf{s}$ \\
\cline { 3 - 6 } & & $\mathbf{a}$ & $\mathbf{b}$ & $\mathbf{c}$ & $\mathbf{d}=\mathbf{a}^{*} \mathbf{b}^{*} \mathbf{c}$ \\
\hline 1 & $13^{*}$ & 2.0 & 1.14 & 18.7 & 42.6 \\
2 & 15 & 2.2 & 1.14 & 18.7 & 47.5 \\
3 & 17 & 2.5 & 1.14 & 18.7 & 53.9 \\
4 & 19 & 2.7 & 1.14 & 18.7 & 58.2 \\
\hline \hline
\end{tabular}

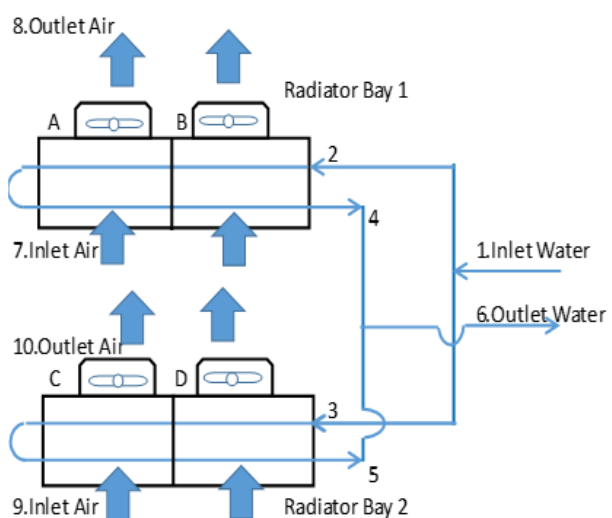

(a)

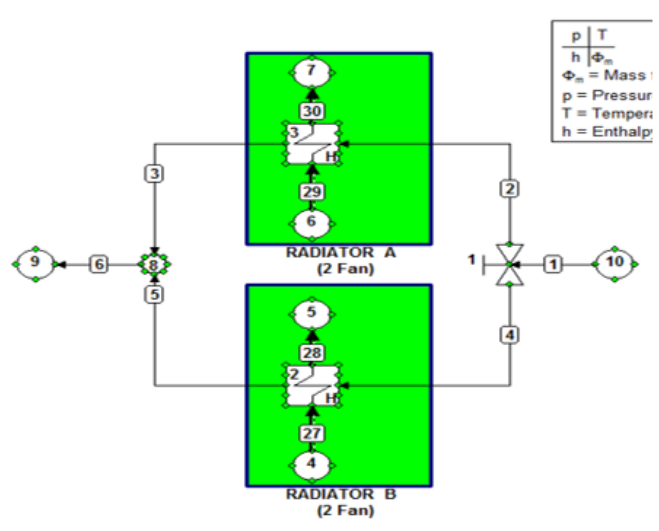

(b)

Figure 4. Modeling Radiator (a). Radiator flow scheme. (b) radiator modeling in Cycle Tempo

TABLE 3.

EXPERIMENTAL VALIDATION AND OFF-DESIGN SIMULATION WITH 4 FANS

\begin{tabular}{lllllll}
\hline \hline No & \multicolumn{2}{c}{ Parameter } & Perhitungan & Cycle Tempo & Selisih & Error \\
\hline 1 & P2 & Bar & 7.5 & 7.5 & & \\
2 & T2 & C & 49 & 49 & & \\
3 & $\dot{m} 2$ & $\mathrm{~kg} / \mathrm{s}$ & 24.73 & 24.73 & & \\
4 & P4 & Bar & 6.5 & 6.5 & 0 & $0.00 \%$ \\
5 & T4 & C & 46 & 46 & & \\
6 & $\dot{m} 4$ & $\mathrm{~kg} / \mathrm{s}$ & 24.73 & 24.73 &
\end{tabular}




\begin{tabular}{|c|c|c|c|c|c|c|}
\hline 7 & P7 & Bar & 1 & 1 & & \\
\hline 8 & T7 & C & 34 & 34 & & \\
\hline 9 & $\dot{m} 7$ & $\mathrm{~kg} / \mathrm{s}$ & 85.12 & 85.12 & \multirow{4}{*}{-0.01} & \multirow{4}{*}{$0.03 \%$} \\
\hline 10 & P8 & Bar & 0.9 & 0.9 & & \\
\hline 11 & T8 & C & 37.71 & 37.71 & & \\
\hline 12 & $\dot{m} 8$ & $\mathrm{~kg} / \mathrm{s}$ & 85.12 & 85.12 & & \\
\hline 13 & $\dot{q}$ & $\mathrm{Kw}$ & 312.15 & 312.15 & -0.55 & $0.18 \%$ \\
\hline
\end{tabular}

From schematic in Figure 4 (a), the model is made in the tempo cycles such as Figure 4 (b) and the data from table Figure 2 (b) also from table fig 3 (d) and the value of $U$ * A of the condition when operated with 4 fan at $13^{\circ}$. then the result is calculated by simulation in validation like figure 4 (c) with error value below $5 \%$, so the off-design model can be used to simulate the next variation.

\section{ANALYSIS AND SIMULATION}

The Mass of Air Flow capacity obtained from the velocity data of each variation $2^{\circ}$ of the current blade fan angle blade with the operation data calculated by the formula:

$$
\dot{\boldsymbol{m}}=\rho \mathrm{x} \text { v x A }
$$

$\dot{\boldsymbol{m}}=$ mass capacity $(\mathrm{kg} / \mathrm{s})$

$\rho=$ air density at $34^{\circ} \mathrm{C}$

$\mathrm{v}=$ air velocity $(\mathrm{m} / \mathrm{s})$

$\mathrm{A}=$ area of radiator per fan $\left(\mathrm{m}^{2}\right)$

The calculation of heat transfer is [8]:

$$
\dot{q}=\dot{m} \cdot\left(h_{\text {in }}-h_{\text {out }}\right)
$$

$\dot{\boldsymbol{q}}=$ Heat (Watt)

$\mathrm{h}=$ Enthalpy $(\mathrm{kj} / \mathrm{kg})$

The calculation of off-design cycle using tempo value (U * A) 'which is calculated from the value of the variation of the order rate with the given value of $U *$ A exists with the formula [6].

$$
(U A)^{\prime}=U A *\left(\frac{\Phi_{m}}{D S M A S 1}\right)^{\eta}
$$

$$
\begin{aligned}
\mathrm{U} & \text { heat transfer capacity rate }\left(\mathrm{kW} / \mathrm{m}^{2} \mathrm{~K}\right) \\
\mathrm{DSMAS1} \text { or } 2 & \text { design mass flow primary or secondary } \\
& \text { side }(\mathrm{kg} / \mathrm{s})
\end{aligned}
$$

The log mean temperature difference is calculated on this formula [9]:

$$
\Delta T_{\text {LMTD }}=\frac{\left(T_{2}-T_{8}\right)-\left(T_{4}-T_{7}\right)}{\ln \frac{\left(T_{2}-T_{8}\right)}{\left(T_{4}-T_{7}\right)}}
$$

$\Delta T_{L M T D}=$ Log mean temperature difference $\left({ }^{\circ} \mathrm{C}\right)$

$\mathrm{T}_{2}=$ Radiator inlet water temperature $\left({ }^{\circ} \mathrm{C}\right)$

$\mathrm{T}_{4}=$ Radiator outlet water temperature $\left({ }^{\circ} \mathrm{C}\right)$

$\mathrm{T}_{7} \quad=$ Radiator inlet air temperature $\left({ }^{\circ} \mathrm{C}\right)$

$\mathrm{T}_{8} \quad=$ Radiator outlet air temperature $\left({ }^{\circ} \mathrm{C}\right)$

And the existing $U$ value is obtained from [9]

\section{RESULT AND DISCUSSION}

From the measurement results can be refers on fig 5. as the angle of the fan blade is reduced from 3 to 11 , the air velocity became reduced. instead on the blade angle greater than $13^{\circ}$ the air velocity increase which followed with the motor current This condition will be continues along as the blade angle increases, but at blade fan angle $21^{\circ}$ position then there is an velocity decreasing with Higher Noise indication and the motor current too. This indicates that Stall takes place in this blade fan angle and the experiment was limited in this angle to avoid high of the vibration.

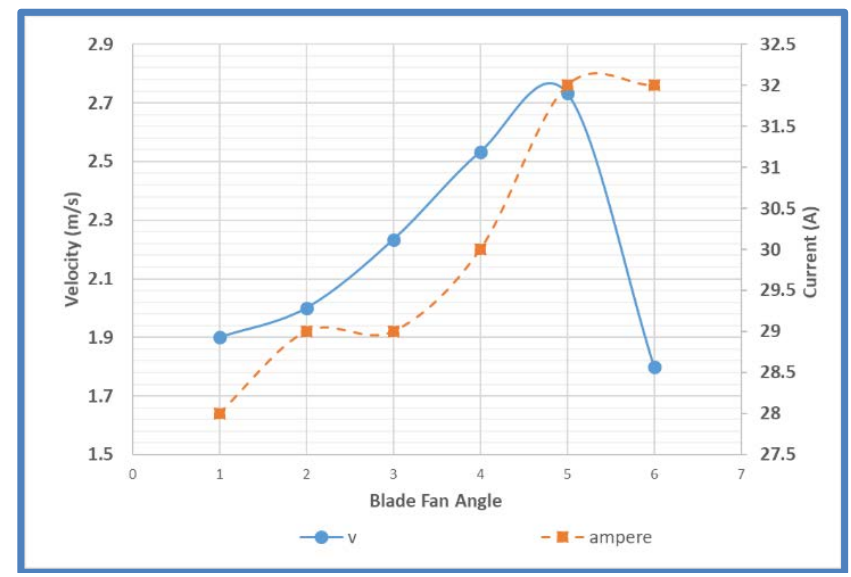

Figure 5. Graph of air velocity and current of motor to blade fan angle

The velocity value obtained from each experimental experiment in the off-design cycle model is obtained from the outlet temperature data of each bay radiator, ie T4 is the outlet of temperature bay 1 with the fan 1 operation, T5 is the outlet temperature bay 2 with the 2-fan operation and T6 is the header outlet of the pipe incorporation 4 and pipe 5. From figure 6 it can be seen that T4 in all variations of blade angle has a value above the maximum temperature limit of $46^{\circ} \mathrm{C}$, while $\mathrm{T} 5$ in all variations of blade angle has a value below the maximum temperature limit, the two points are then mixed in the header (T6) where it can be seen that there is a value greater than $\mathrm{T}$ max and smaller than Tmax. To get the blade angle value with $46{ }^{\circ} \mathrm{C}$ temperature outlet then $\mathrm{T} 6$ graph is done by linear regression and obtained by equation: $y=-0.22 X+46.368$ With $\mathrm{y}=46$ then:

$$
X=\frac{(46.368-46)}{0.022}=16.7
$$




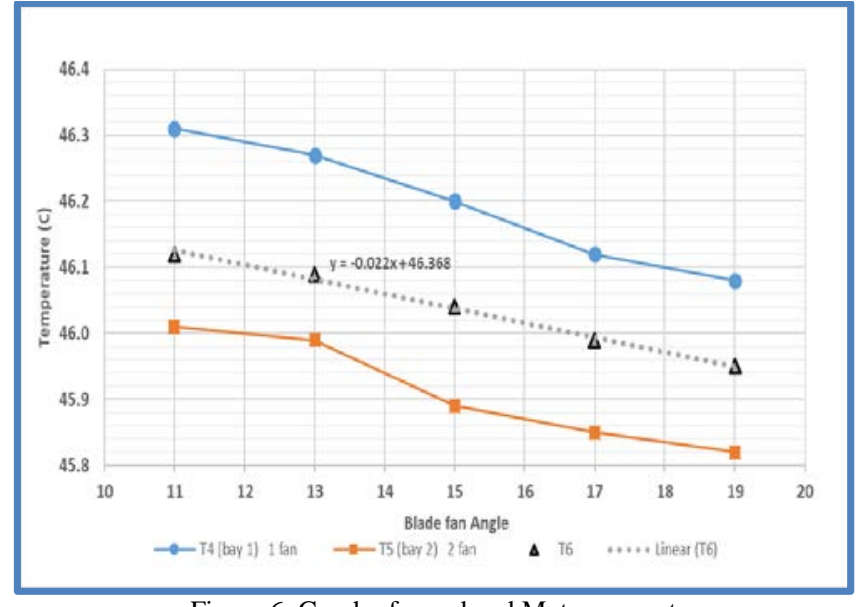

Figure 6. Graph of speed and Motor current

From the simulation on each variation of the blade fan angle angle with 3 fan operation can be obtained the heat data discarded shown in fig 7 . With regresi obtained equation:

$$
y=-0.1708 x^{3}+7.6089 x^{2}-104.89^{x}+1051.6
$$

with $\mathrm{x}=16.7^{\circ}$, the total exhausted heat is $626.49 \mathrm{~kW}$ where the minimum value required is $623.91 \mathrm{~kW}$. meaning that below the $16.7^{\circ}$ angle with 3 fan operation, the radiator is unable to remove the minimum heat that must be discarded, and above the blade angle of $16.7^{\circ}$ up to $19^{\circ}$ the radiator is able to remove the minimal heat that must be discarded by the ACWS.

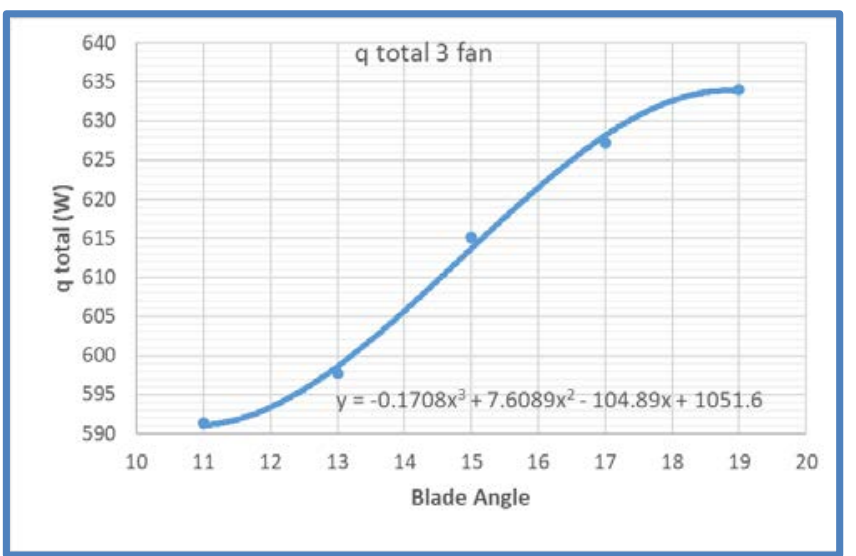

Figure 7. Graph Total $\dot{q}$ with 3 fans per variation of the blade fan angle

\section{CONCLUSION}

The Conclusion of this research:

- The Blade Angle of the ACWS Up Fan at Muara Karang it can be improved from $13^{\circ}$ until to $19^{\circ}$ for increasing the suction air capacity of radiator fan.

- The addition of the blade angle, it can be increasing the capability of the radiator for the heat transfer performance. On $16.7^{\circ}$ angle position, the Heat Transfer value at $\mathrm{q}=623.91 \mathrm{~kW}$, this condition similar with using 4 fans operation at $13^{\circ}$

- Use the angle blade settings in the fan on $16.7^{\circ}$ position, the ACWS system can operate with 3 fans only, because the temperature outlet condition of the radiator is similar with the ACWS existing.

\section{REFERENCES}

[1] GE Power, "9E Advanced Gas Path A Power LifeMax* Solution.” 2016.

[2] GE Power, “Extendor ${ }^{\mathrm{TM}}$ Combustion System.” GE Power, 2008.

[3] GE Power, "MS 9000 Service Manual Turbin Accessories and Generator, GEK-98786, Volume 1.” GE Power.

[4] S. Bose, "Improve air-cooled heat exchanger performance," CEP Magazine, pp. 1-7, Jan-2017.

[5] M. J. Izadi and A. Falahat, "Effect of blade angle of attack and hub to tip ratio on mass flow rate in an axial fan at a fixed rotational speed," in ASME 2008 Fluids Engineering Division Summer Meeting collocated with the Heat Transfer, Energy Sustainability, and 3rd Energy Nanotechnology Conferences Volume 1: Symposia, Parts A and B, 2008, pp. 903-913.

[6] ASIMPTOTE, Cycle-tempo manual reference guide. HeeswijkDinther, Netherlands: ASIMPTOTE.

[7] R. D. Bock, "The performance of an axial flow fan in a small scale A-frame test facility.," 2017. [Online]. Available: https://scholar.sun.ac.za/handle/10019.1/102757.

[8] M. J. Moran and H. N. Saphiro, Fundamentals of Engineering Thermodynamics. Chichester: John Wiley \& Sons Inc, 2011.

[9] F. P. Incropera, D. P. DeWitt, T. L. Bergman, and A. S. Lavine, Fundamentals of heat and mass transfer., 6th ed. Danvers (MA): John Wiley \& Sons, 2007. 